\title{
Mathematical Problem Solving for Engineering Students
}

\author{
Robert Leland ${ }^{1}$, James Richardson ${ }^{2}$, Tan-Yu Lee ${ }^{3}$, John Dantzler ${ }^{4}$ \\ ${ }^{1}$ Electrical and Computer Engineering Dept. $/{ }^{2}$ Civil and Environmental \\ Engineering Dept. $\left.\right|^{3}$ Mathematics Dept., University of Alabama $/{ }^{4}$ Censeo \\ Research, Inc.
}

\section{Introduction}

At the time of the Second World War, Sir Lawrence Holt recognized that younger sailors in the British merchant marine were unable to perform their duties, especially in emergency situations, often leading to loss of life. He called on educator Kurt Hahn for help. In 1941, Hahn began a program that has become known as Outward Bound. This program builds self-confidence and ability by confronting young people with challenging tasks, such as climbing a mountain ${ }^{11}$. We face a similar situation in engineering education. Students arrive at universities frequently lacking the mathematics and problem solving skills needed to succeed as engineering students. These deficiencies are often not remedied as the students pass through the curriculum, leading to low retention rates and shortages of US educated engineers.

In response, we are developing a course and materials in mathematical problem solving for firstyear engineering students who are either Calculus-ready or one semester away from Calculus. Only pre-calculus mathematics is used in the course. This effort supported as an NSF CCLIEMD proof of concept study. The goal of the course is to increase students' mathematical problem solving skills in a way that transfers to future coursework. This course differs from many problem solving courses in two ways. First, like Outward Bound, the course will emphasize the solution of hard problems, so that students develop a sense of self-efficacy in mathematics that will transfer to future coursework. Second, the course will emphasize explanations, including training and practice in both self-explanation and explaining problems and solutions to others. We believe these emphases are essential for students to develop mathematics and problem solving skills that will transfer to their future coursework.

\section{Rationale for the Course}

A simple problem statement for the course we are developing is to teach mathematical problem solving in a way that leads to transfer of knowledge and skills to future coursework. We focused on the solution of difficult, but well defined problems because this is a major deficiency in the students we see. We also included the formulation of real-world problems, which usually are not well defined, contain both incomplete and unnecessary data, and lack a clearly defined objective. Engineers need a solid foundation in solving well defined problems in order to solve these real world problems. 
It is especially important for students to solve problems in which they must select the mathematical tools to solve the problem ${ }^{13}$. For example, the use of cumulative review problems, drawing on all previous material, resulted in increased problem solving ability ${ }^{10}$. In contrast, typical textbook exercises at the end of the chapter rely mainly on recent content, which gives students sufficient clues to select solution techniques without developing the understanding required to apply those concepts in new contexts. Although we do review math concepts, we are not primarily introducing new math content, so we can more easily introduce problems without obvious clues to the mathematical tools needed.

Problem solving courses for engineers exist at many universities. Specific instruction about the problem solving process has had positive effects, but often did not transfer to future coursework without significant integration into the entire four-year curriculum, as in the McMaster Problem Solving Program ${ }^{23}$. This is difficult to accomplish at most institutions. Many introductory problem solving courses provide the students with a 4-6 step method, but do not emphasize explanation and hard problems to develop the cognitive skills required, and facilitate transfer. We believe an emphasis on hard problems and explanation is critical for transfer of skills. For example, in cooperative learning classrooms, making explanations only benefited the student explainer if thought and elaboration were required ${ }^{21}$, that is, if the problems were hard.

For successful transfer to occur, the students must understand clearly how to solve problems, and not back off when confronted with a difficult problem ${ }^{3}$. To achieve transfer, several factors are important: i) Self-Efficacy, or students' confidence in their ability to solve mathematical problems $^{12}$; ii) Learning with understanding. Students must understand the fundamental principles behind solutions to problems ${ }^{3}$; iii) Beliefs. Students must believe the concepts they have learned are real, and will still be real in a different context, such as the next course.

Problem solving ability and transfer depend not only on students' knowledge, but also their perception of their own expertise and ability ${ }^{12}$. Restricted to a particular domain, such as mathematics, this is called self-efficacy, a kind of domain specific self-confidence ${ }^{2}$. Students who lack self-efficacy in mathematics back away from math problems, and mathematically oriented subjects like engineering, leading to failure and lack of retention ${ }^{1}$. Addressing selfefficacy in mathematics early in the curriculum may significantly increase the retention of female and minority students in engineering. In a statistical study, accounting for self-efficacy mediated the effects of race and gender on problem solving ${ }^{12}$, supporting this expectation.

Self-efficacy is promoted in four ways ${ }^{2}: 1$. Mastery experiences, where students demonstrate mastery by overcoming obstacles through effort. We promote mastery by using hard problems, and emphasizing explanations. 2. Reinforcement by seeing peers achieve mastery. We use cooperative learning, teamwork, and class presentations to create a learning environment in which students see the mastery experiences of peers. 3. Social encouragement. Students were repeatedly given encouragement that the problems are hard, but can be solved with hard work. 4 . Students must learn to manage emotional and physical reactions, such math anxiety, or the knot in the stomach when facing a challenging problem on a test.

Transfer requires learning with understanding ${ }^{3}$. To achieve this we have the students explain problems, solutions and math concepts in small groups and class presentations. Specific 
instruction in making explanations was used to prepare the students. Articulated explanations have been identified as one of the strengths of cooperative learning ${ }^{18}$. However students often require training to become good explainers ${ }^{15}$.

Worked-out examples play a prominent role in engineering education. Learning from worked-out examples requires active processing that often does not occur in our students, creating an illusion of understanding that results in poor test performance. ${ }^{4}$. Successful students practice selfexplanation, and process worked out examples by relating solution steps to basic principles, and anticipating the next step $^{7,14}$. Students who practiced self-explanation performed better on both initial learning, and transfer of knowledge to different contexts. When students process examples by self-explanation, or explaining the example to themselves, learning, mastery and problem solving are significantly advanced ${ }^{19,21,22}$. Training in self-explanation has been shown to be effective $^{14}$. We used training and practice in self-explanation through specific instruction, and exercises where students explained worked examples. Examples of explanation exercises include developing explanations for the purpose and concepts involved in each step of a worked example, or developing a frequently asked questions list for a worked example.

Student beliefs are a major factor in problem solving ${ }^{17}$. Students must believe the concepts they have learned are real, and will still be real in a new context. Connecting concepts with reality gives students confidence those ideas will still be true in the next class. The use of physical, hands-on exercises integrally connected to mathematics problems was used to convince students that the ideas they are learning apply in the real world. Some examples used in the class included: taking apart a computer mouse and determining its resolution (smallest detectable motion), determining the weight of the bar on a see-saw using only measurements of distance and peoples' weights, determining the surface area of a soda can. Students also solved extended problems for a floppy disk drive and robot arm for which they saw the actual hardware involved.

Despite the focus on pre-calculus mathematics, the course was not remedial, and the problems addressed were more difficult than those in a standard pre-calculus math class. Uri Treisman at Berkeley pioneered this approach of using hard problems, with good results ${ }^{20}$. A survey of MIT graduates listed one of the three main things they learned as undergraduates was to not be afraid of hard problems (self-efficacy).

Metacognition, or an awareness of how you are thinking, plays an important role in most problem solving courses, and training in metacognition has lead to gains in problem solving and math skills ${ }^{6,8}$. Sometimes this is expressed as a 4-6 step process for solving problems. This is misleading, as following the steps mindlessly will not solve all problems. To keep things simple, we followed Polya's model of Understand, Plan, Do, Reflect ${ }^{13}$. As indicated by Polya and others, we found the key area students needed to grow in was understanding the problem. Students were constantly made aware they should invest time in understanding a problem first, and developing a plan of attack before jumping in and performing a lot of computations.

\section{Description of the Course}

In Fall 2004 the course was taught as one of eight sections of GES 131 Foundations of Engineering at the University of Alabama. Two sections of GES 131 were set apart for first 
semester freshmen who had the appropriate math placement scores (Calculus ready or one semester before Calculus). One section received the experimental problem solving instruction, while the other served as a control. About 35 students were enrolled in each section. Students were assigned to these sections during summer advising, without knowledge of the experimental nature of our section, so there was no "volunteer effect." All students in the experimental and control sections signed informed consent forms as required by the Institutional Review Board (IRB). The experimental and control sections were formed to balance ACT scores as much as possible.

GES 131 is a two credit course that meets three times per week, twice for 50 minutes, and once for 110 minutes. The experimental and control sections met MW 8-8:50 am and F 8-9:50 am in adjacent rooms. This arrangement was made to allow the transfer of students from one section to the other to balance ACT scores at the beginning of the semester. As it turned out, no such transfers were necessary, and ACT scores were fairly balanced between the two sections. It should also be noted that two additional honors sections of GES 145 Foundations of Engineering I (Honors) were taught that semester, so many of the top students $(20 \%$ of them) were not included in the experimental or control sections. A few students who were eligible for the honors sections (GES 145) were in the regular sections (GES 131), so the removal of these high scoring students was not total and absolute.

The course consisted of specific instruction (lecture), problem solving practice, active and cooperative learning exercises, home assignments, 5 tests, quizzes, and a design project.

During the first half of the course we used four lectures for an integrated review of mathematics concepts. Each lecture integrated several math concepts together into a single problem. Two of these classes also involved Excel exercises. We also used the Schaum's Outline on Precalculus ${ }^{16}$ by Fred Safier as a required text to create a baseline of available mathematics knowledge. Homework was assigned out of this book for review as well. The other textbook used was The New Way Things Work ${ }^{9}$ by David Macauley. This book was used to help students look at complex devices in terms of simple machines and identify common basic physical principles. The identification of common basic principles in different situations supports problem solving and transfer. This book was well received by the students, and often was used for reading assignments on devices to prepare students for upcoming problems.

Since the course focused on problem solving skills rather than mathematical content, no attempt to introduce new mathematics concepts was made. We reviewed concepts of solving simultaneous equations, polynomial curve fitting, plane geometry involving triangles and circles, trigonometry, and exponential and logarithmic functions. Numerical exercises in Excel accompanied some of these reviews. Each review involved several math concepts integrated into a single problem. Students were also assigned problems in Schaum's Outline on Precalculus ${ }^{16}$ for math review.

Specific instruction (Lecture) was given on the following topics:

1. Overview of the problem solving process following Polya's framework of Understand, Plan, Do, Reflect. These were presented not as steps, but as different activities involved 
in problem solving. Considerable attention was paid to developing a mathematical understanding of the problem, and this was an emphasis of the course.

2. Self-explanation of worked examples.

3. Working in Teams.

4. Written and oral communication, especially geared to help students explain their own solutions.

5. Ethics, with a focus on the immediate student issue of academic integrity (cheating).

6. Metacognition: Students being aware of and controlling which of the four problem solving activities they are currently involved in.

7. Drawing good diagrams that facilitate problem solving. A majority of the problems worked involved geometry in some way.

In general, very little time was spent lecturing, and most class periods consisted of active and cooperative learning exercises. These exercises included:

1. Finding the weight of the bar of a see saw near the student recreation center using only distance measurements and the weights of the students.

2. Estimating the surface area of a soda can.

3. Finding conditions under which a board across two sawhorses will not tip over.

4. Finding the resolution of a computer mouse.

5. Finding the shape of the timing signal produced by a $5 \frac{1 / 4}{4}$ floppy disk drive.

6. Finding a trajectory for a two joint robot arm from one point to another in joint coordinates while avoiding a barricade.

7. Finding the rate of ascent for a person in a lawn chair lifted by helium balloons (based on a real incident).

8. Finding the weight of a sinking ship.

9. Additional exercises involving geometry and simultaneous equations.

10. Problems involving the passage of time, with answers that were a function of the time variable $\mathrm{t}$.

Throughout the semester we emphasized the importance of achieving a precise mathematical understanding of the problem. This understanding is represented by developing a mental model of the problem, usually a diagram or set of equations that facilitate a solution. Thus understanding the problem is much more than just reading comprehension. As many authors, including Polya ${ }^{13}$ have indicated, this is where most students have difficulty. This was also our experience. Much effort was needed to get students to do the work to understand the problems before plunging into computation. We especially emphasized coming up with a good diagram, which includes the problem data and problem goal, and represents the key issues in the problem. Many problems included extra data, so the students had to discern which data was relevant.

Problems involving the passage of time presented a challenge to many students, as did the idea of coming up with an answer that was a function of time rather than a number. This functionconcept issue may explain the difficulties our students frequently have in later courses, especially Dynamics, and the transient analysis of electrical circuits in the first circuits course. We intend to emphasis passage of time problems much earlier in Spring 2005. Passage of time was involved in the robot arm and disk drive problems, and several other smaller problems. 
We have found that quizzes are an excellent tool for communicating priorities to students, and saying "Yes, you really need to know this." Therefore quizzes were used to test students' ability to understand problems and draw good diagrams. Quizzes would require students to draw the diagram for a problem, but not give credit only for the diagram, and not for the solution itself.

To build self-efficacy, students were selected to present their solutions to in-class exercises and home assignments. Thus the students saw peers succeeding in solving the problems, and the students explaining their solutions develop confidence and deeper insight. Many times students would be called to present partial solutions, or even just a good diagram for the problem. This communicated a positive value of the work done to understand a problem. Students who presented were always applauded, celebrating good work.

Exams were graded in such a way that a large amount of partial credit was assigned for successfully doing the work of understanding a problem. This might be $40-60 \%$ of the credit of a problem for coming up with a good diagram. This reinforced the value of understanding the problem.

\section{Assessment Methods}

Assessment was both formative and summative. Formative assessment focused on what the students found helpful or not. Summative assessment focused on changes in student problem solving ability and self-efficacy. Transfer will be assessed by student performance on specific problems in future Calculus and Physics problems.

For summative assessment we developed a six question math problem solving test designed for a 60 minute time period. A copy of this test is included at the end of this paper. Students were informed the test would be counted toward their grade on a good faith attempt basis. Question one was a very simple estimation problem, which did not involve a problem solving process, so we consider the test results with and without this question. The remaining questions were fairly difficult, and involved substantial problem formulation. For assessment purposes, each problem was graded on a scale of $0-4$, with 4 being the highest. Algebra errors were not counted, however students arriving at a correct answer by a trial error process received only a score of 2/4. This test was administered to students in all eight sections of GES 131 at the beginning of the semester as a pre-test, and again at the end of the semester as a post test. This test was also administered to students in the two honors sections of GES 145 as a pre-test. The pre-test results of the honors sections were very high, and a post-test was not given to the honors sections.

We also developed a 25 question self-efficacy scale that focused on mathematical problem solving for students at the level of engineering freshmen. A copy of this questionnaire is included at the end of this paper. Existing self-efficacy scales were designed for students at a much lower level, and would not be useful for this study. Two types of questions were used on the scale. The first section of 10 questions asked students to agree or disagree on a scale of $1-$ 10 with statements such as "I am good at solving mathematics problems," with 1 being strongly disagree, 3: Disagree, 5: Neutral, 8: Agree, 10: Strongly agree. The second section of 15 questions asked students to express their confidence in their ability to solve specific math 
problems on a scale of $1-10$, with 1 being Cannot solve it at all, 5: Moderately certain I can solve it, and 10: Certain I can solve it. A copy of the self-efficacy scale we developed is given at the end of this paper. This self-efficacy assessment was given to all 8 sections of GES 131 at the beginning of the semester, and repeated for the experimental and control sections at the end of the semester. Further analysis is needed to refine and validate this instrument.

For formative assessment, we asked students to write one-minute papers several times during the semester. Student comments on formal course evaluations are not available. Students identified what aspects of the course they found helpful, and what could be improved. Instructor observations were also part of formative assessment.

\section{Assessment results}

The results of the pre and post math problem are shown below. Results for both all six problems (out of 24 points), and problems $2-6$ (out of 20 points) are reported separately, since problem 1 did not involve significant problem solving. Results for all six problems are shown in Table 1, and results for problems 2-6 are shown in Table 2. Results are only included for students taking both the pre and post tests. The effect size was calculated using the standard deviation of the control group. The effect sizes using the pooled standard deviation are .154 for questions 1-6 and .614 using questions 2-6.

\begin{tabular}{|l|l|l|l|l|l|l|l|}
\hline & $\begin{array}{c}\text { Pre-Test } \\
\text { Mean }\end{array}$ & $\begin{array}{l}\text { Pre-Test } \\
\text { St. Dev. }\end{array}$ & $\begin{array}{c}\text { Post-Test } \\
\text { Mean }\end{array}$ & $\begin{array}{c}\text { Post-Test } \\
\text { St. Dev. }\end{array}$ & $\begin{array}{c}\text { Delta } \\
\text { Mean }\end{array}$ & $\begin{array}{c}\text { Delta } \\
\text { St. Dev. }\end{array}$ & $\begin{array}{c}\text { Effect } \\
\text { Size }\end{array}$ \\
\hline $\begin{array}{l}\text { Experimental Problem } \\
\text { Solving Section N=26 }\end{array}$ & 12.27 & 4.61 & 14.92 & 4.41 & 2.65 & 3.85 & .148 \\
\hline Control Section N=30 & 9.5 & 4.47 & 11.53 & 4.07 & 2.03 & 4.18 & \\
\hline
\end{tabular}

Table 1. Mathematical Problem Solving Test Results for Questions 1-6 (all questions).

\begin{tabular}{|l|l|l|l|l|l|l|l|}
\hline & $\begin{array}{c}\text { Pre-Test } \\
\text { Mean }\end{array}$ & $\begin{array}{l}\text { Pre-Test } \\
\text { St. Dev. }\end{array}$ & $\begin{array}{c}\text { Post-Test } \\
\text { Mean }\end{array}$ & $\begin{array}{c}\text { Post-Test } \\
\text { St. Dev. }\end{array}$ & $\begin{array}{c}\text { Delta } \\
\text { Mean }\end{array}$ & $\begin{array}{c}\text { Delta } \\
\text { St. Dev. }\end{array}$ & $\begin{array}{c}\text { Effect } \\
\text { Size }\end{array}$ \\
\hline $\begin{array}{l}\text { Experimental Problem } \\
\text { Solving Section N=26 }\end{array}$ & 9.19 & 3.91 & 12.58 & 3.88 & 3.38 & 3.16 & .658 \\
\hline Control Section N=30 & 7.3 & 3.88 & 8.87 & 3.39 & 1.57 & 2.75 & \\
\hline
\end{tabular}

Table 2. Mathematical Problem Solving Test Results for Questions 2-6.

When questions 1-6 are considered, the results do not show a statistically significant change between the experimental and control groups.

\subsection{Analysis of Pre-Post Data from the First Semester Questions 2 through 6 only.}

The following analyses are only for questions 2 through 6 on the pre and post tests. 


\begin{tabular}{|c|c|c|c|c|c|}
\hline & & Mean & Median & $\begin{array}{l}\text { Standard } \\
\text { Deviation }\end{array}$ & Range \\
\hline \multicolumn{6}{|l|}{ Control $(n=30)$} \\
\hline \multirow{2}{*}{$\begin{array}{c}\text { Avg ACT }=24.4 \\
\text { Avg Math ACT }=25.5\end{array}$} & Pre & 7.3 & 6.0 & 3.88 & 2 to 17 \\
\hline & Post & 8.9 & 9.0 & 3.39 & 1 to 16 \\
\hline \multicolumn{6}{|l|}{ Experimental $(n=26)$} \\
\hline Avg $\mathrm{ACT}=26.0$ & Pre & 9.2 & 9.5 & 3.91 & 1 to 14 \\
\hline Avg Math ACT $=27.2$ & Post & 12.6 & 12.0 & 3.88 & 4 to 20 \\
\hline
\end{tabular}

Table 3: Descriptive Statistics from entire Sample

There was a 1.6 point increase from pre to post average score for the control group and a 3.4 point increase for the experimental group. The standard deviation from the mean for each group and each test are very similar indicating a similar pattern of scores over groups and testing. The ACT scores between groups are not significantly different at the .05 alpha level $(t=-1.79, \mathrm{df}=49$, $p=.080$ ), and the Math ACT scores between groups are not significantly different at the .05 alpha level $(t=-1.91, \mathrm{df}=49, p=.062)$. It should be noted that while these ACT scores are not significant at the .05 level, they both are approaching significance and could have an effect on group differences. Because of the potential differences in group ability, the Math ACT scores will be used as a covariate in between groups analysis to control for this effect.

A repeated measures analysis of variance (ANOVA) was computed using pre-post test scores as the within groups test variable, and control/experimental status and the between group factor. As mentioned above, Math ACT score was used as a covariate. Since Math ACT was used to control for ability, the total number of subjects drops to 51 as opposed to 56 . Five students did not have Math ACT scores available.

The within group analysis shows that there is a test by group interaction effect $[F(1,48)=5.404$, $p=.024]$, however, there is not a test main effect $[F(1,48)=0.746, p=.392]$. These results indicate that there is no statistically significant difference between pre and post tests overall, but there is a statistically significant difference between the slopes of the pre-post test difference by group.

The between group differences show that there is a difference in pre-post scores between groups $[F(1,48)=4.641, p=.036]$, and there is a significant difference in Math ACT scores between groups $[F(1,48)=13.882, p=.001]$.

Univariate ANOVAs indicate that while the post test scores between groups are significantly different $[F(1,48)=9.509, p=.003]$, the pre test scores between groups are not significantly different $[F(1,48)=0.856, p=.360]$. 


\section{Estimated Marginal Means by Groups Math ACT as Covariate}

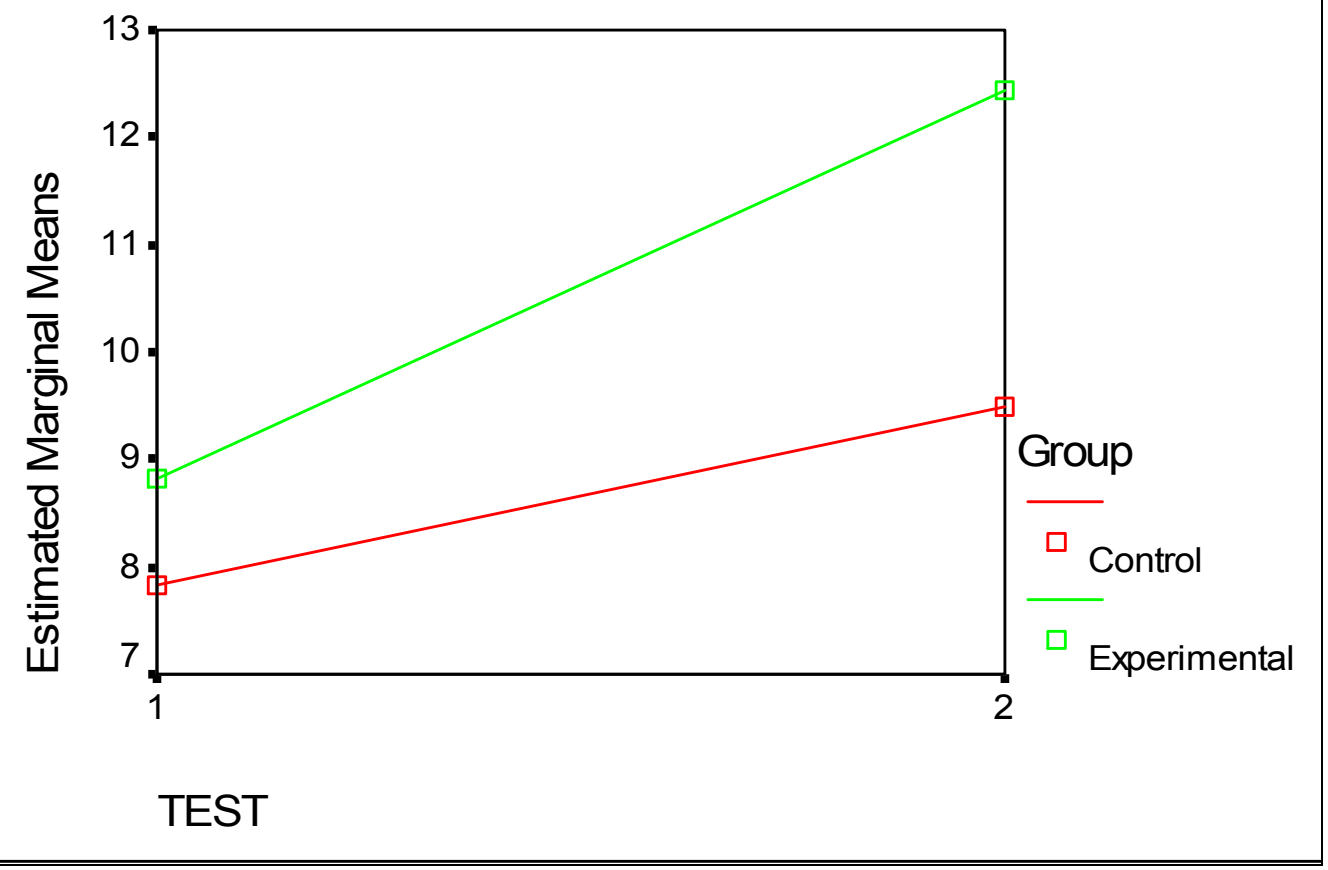

Figure 1. Pre and Post Test Marginal Means for the Experimental and Control Groups.

The results show that the experimental and control groups had significantly different slopes based on pre and post test scores. This can be interpreted as the experimental group showing statistically significant improvement over the control group from pre to post testing. The significance test by group within subjects interaction effect is the indicator of this difference, and the significant between groups "group" effect is an indicator that the two groups do not have equal overall mean scores. Univariate ANOVAs indicate that the two groups started in the same place by having similar pre-test scores, however, the post test scores are significantly different.

Based on these data, the experimental method resulted in better post test outcomes than the traditional method.

We can also consider the percent of correct answers (4 out of 4 points) on problems 1-6 and 2-6. These are shown in Table 4. Once again, the results on questions 1-6 are comparable for both sections, however the results for questions 2-6 show significant differences. 


\begin{tabular}{|l|c|c|c|c|c|c|}
\hline & \multicolumn{3}{|c|}{ Questions 1-6 } & \multicolumn{3}{c|}{ Questions 2-6 } \\
\hline & Pre-Test & Post-Test & Delta & Pre-Test & Post-Test & Delta \\
\hline $\begin{array}{l}\text { Experimental Problem } \\
\text { Solving Section N=26 }\end{array}$ & 32.1 & 45.5 & 13.4 & 23.8 & 46.9 & 23.1 \\
\hline Control Section N=30 & 24.4 & 35.0 & 10.6 & 20.7 & 31.3 & 10.6 \\
\hline
\end{tabular}

Table 4. Percent of correct answers (4 out of 4 points) on the Mathematical Problem Solving Test.

Considering the scores on questions $2-6$ only, $50 \%$ of the students in the experimental section increased their scores by 4 points or more out of 20 from the pre to post test, compared to $20 \%$ of the students in the control group. $26.9 \%$ of students in the experimental group had post test scores of 16 out of 20 or above, compared to $3.3 \%$ in the control group. Only one student, who was in the control group, had a score of 16 or higher on the pre-test.

The self-efficacy scales showed only a small increase (about 8 out of 250) in average score from the pre and post course questionnaires. Six students (26\% of 23 students) in the experimental group increased their score by at least 20 points out of 250 . Three students ( $11 \%$ of 28 students) in the control group showed such an increase. The mean scores for both sections are shown in Table 5.

\begin{tabular}{|l|c|c|c|c|c|c|c|}
\hline & $\begin{array}{c}\text { PreTest } \\
1-10\end{array}$ & $\begin{array}{c}\text { PreTest } \\
11-25\end{array}$ & $\begin{array}{c}\text { PreTest } \\
\text { Total }\end{array}$ & $\begin{array}{c}\text { PostTest } \\
1-10\end{array}$ & $\begin{array}{c}\text { PostTest } \\
11-25\end{array}$ & $\begin{array}{c}\text { PostTest } \\
\text { Total }\end{array}$ & $\begin{array}{c}\text { Delta } \\
\text { Total }\end{array}$ \\
\hline $\begin{array}{l}\text { Experimental Problem } \\
\text { Solving Section N=23 }\end{array}$ & 74.48 & 125.83 & 200.3 & 76.00 & 132.74 & 208.74 & 8.43 \\
\hline Control Section N=28 & 77.09 & 131 & 208.09 & 75.57 & 135 & 210.57 & 2.48 \\
\hline
\end{tabular}

Table 5. Self-Efficacy scale means for the Experimental and Control sections.

One minute papers by the students consistently showed that the students felt that working in teams was a very positive experience. They liked hands on exercises, and the two textbooks. The students indicated they would like a higher level of organization in the course, with clearer expectations. These comments lead to changes in the way assignments were made. In general the student teams were self selected, and this worked well.

Instructor observations showed that students were working well in teams, but needed more work in problem formulation and producing adequate diagrams. Students also had difficulty with passage of time problems (functions of time).

\section{Discussion.}

A semester long course for engineering freshmen on mathematical problem solving resulted in improved problem solving abilities, as evidenced by a pre and post test compared with results of a control group. The sample sizes are relatively small, but the results are statistically significant. It was seen by the instructors that the key area students needed to improve in was developing a precise mathematical understanding of the problems. Problems involving the passage of time 
also gave the students considerable difficulty. Addressing this issue early should improve student success rates in differential equations, Dynamics, and Electric Circuits.

This was our first time teaching this course. The authors feel the results were promising, but that there was much room for improvement. In particular many students were still struggling with setting up problems correctly. In the next trial we will devote more time in class to: drawing good diagrams, and recognizing when a diagram is good enough; training students to assess their own degree of understanding of concepts and problems, and diagnose where they need to improve their own problem solving skills; problems involving the passage of time and the function concept; and hands on exercises.

We were pleased to see an interaction between Math ACT scores, our course and post test performance. In a future study we might consider the impact of Math ACT scores, Math Placement scores (given to freshmen at University of Alabama), and pre and post test performance. Probably more interesting to engineering educators would be evidence of improved problem-solving ability in future courses. We plan to compare problem solving performance on final exam questions in future Calculus and Physics classes of students in the experimental and control sections.

\section{Acknowledgement}

This work was supported in part from NSF Grant DUE-0341463 under the Course Curriculum and Laboratory Improvement - Educational Materials Development (CCLI-EMD) program as a proof of concept study.

\section{Bibliographic Information}

[1]. Ashcraft, M. H., "Math Anxiety; Personal, Educational and Cognitive Consequences," Current Directions in Psychological Science, 11 (5): 181-185, Oct. 2002.

[2]. Bandura, A., "Self-Efficacy", in Encyclopedia of Human Behavior, 4: 71-81, V. S. Ramachudran ed., New York, Academic Press, 1994.

[3]. Bransford, J. D., Brown, A. L., Cocking, R. R. eds., How People Learn: Brain, Mind, Experience and School, Expanded Edition, National Academy Press, Washington DC, 2000.

[4]. Chi, M. T. H., Bassok, M. Lewis, M., Reimann, P. Glaser, R., "Self-Explanations: How Students Study and Use Examples in Learning to Solve Problems," Cognitive Science 13, 145-182, 1989.

[5]. Choi, J. I., Hannafin, M., "The Effects of Instructional Context and Reasoning Complexity on Mathematics Problem-Solving," ETR\&D-Educational Technology Research and Development, 45 (3): 43-55, 1997.

[6]. Desoete, A., Roeyers, H. , De Clercq, A., "Can Offline Metacognition Enhance Mathematical Problem Solving?," Journal of Educational Psychology, 95 (1): 188-200, Mar. 2003.

[7]. Hauf, H. M., Fogarty, G. J.. "Analysing Problem Solving Behaviour of Successful and Unsuccessful Statistics Students," Instructional Science 24 (6): 397-409, Nov. 1996.

[8]. Hoek, D., van den Eeden, P. Terwel, J., "The Effects of Integrated Social and Cognitive Strategy Instruction on the Mathematics Achievement in Secondary Education," Learning and Instruction, 9 (5): 427-448, Oct. 1999.

Proceedings of the 2005 American Society for Engineering Education Annual Conference \& Exposition Copyright (C) 2005, American Society for Engineering Education 
[9]. Macaulay, D., The New Way Things Work, Houghton Mifflin Co., 1998.

[10]. Mayfield, K. H., Chase, P. N., "The Effects of Cumulative Practice on Mathematics Problem Solving," Journal of Applied Behavior Analysis, 35 (2): 105-123 Summer 2002.

[11]. Outward Bound: History, outwardboundwest.com/about/history/.

[12]. Pajares, F., Miller, M. D., "Role of Self-Efficacy and Self-Concept Beliefs in Mathematical Problem-Solving - A Path-Analysis," Journal of Educational Psychology, 86 (2): 193-203 June 1994.

[13]. Polya, G., How To Solve It, Princeton University Press, Princeton, NJ, 1945.

[14]. Renkl, A., "Learning Mathematics From Worked-Out Examples: Analyzing and Fostering SelfExplanations," European Journal of Psychology of Education, 14 (4): 4778-488, Dec. 1999.

[15]. Ross, J.A., Cousins, J. B., "Giving and Receiving Explanations in Cooperative Learning Groups," Alberta Journal of Educational Research, 41 (1): 103-121 March 1995.

[16]. Safier, F., Schaum's Outline of Theory and Problems of Precalculus, McGraw Hill, 1998.

[17]. Schoenfeld, A.H., "Reflections on a Course in Mathematical Problem Solving," Research in Collegiate Mathematics Education. III, Schoenfeld, A.H., Kaput, J. Dubinsky, E. eds., American Mathematical Society, Providence, RI, 81-113, 1998.

[18]. Slavin, R.E., Cooperative Learning: Theory, Research and Practice, Prentice Hall, Englewood Cliffs, NJ, 1990 .

[19]. Trafton, J. G, Trickett, S. B., "Note-Taking for Self-Explanation and Problem Solving," Human-Computer Interaction, 2001, Vol. 16, 1-38.

[20]. Treisman, P.M. (Uri), A Study of the Mathematics Performance of Black Studenets at the University of California, Berkeley, Doctoral Dissertation, UC Berkeley, 1985.

[21]. Webb, N. M., "Task Related Verbal Interaction and Mathematics Learning in Small Groups," Journal for Research in Mathematics Education, 22 (5), 366-389, 1991.

[22]. Wong, R.M.F., Lawson, M. J., Keeves, J., "The Effects of Self-Explanation Training on Students' Problem Solving in High-School Mathematics," Learning and Instruction, 12 (2): 233-262, April 2002.

[23]. Woods, D.R., Hrymak, A.N., Marshall, R.R., Wood, P. E., Crowe, C.M., Hoffman, T.W., Wright, J.D., Taylor, P.A., Woodhouse, K.A., Bouchard, C.G.K., "Developing Problem Solving Skills: The McMaster Problem Solving Program,” Journal of Engineering Education, 86(2): 75-91, April 1997.

[24]. "Engineering Criteria 2000," Accreditation Board for Engineering and Technology, Inc, 1997.

\section{Biographical Information}

ROBERT LELAND received a S.B. in Computer Science from MIT in 1978, a M.S. in System Science from UCLA in 1982 and a Ph.D. in Electrical Engineering from UCLA in 1988. From 1989-1990 he was a visiting assistant professor at the University of Minnesota. Since 1990 he has served on the faculty at the University of Alabama in Electrical and Computer Engineering. His research interests include controls, MEMS, and engineering education.

JAMES RICHARDSON received a B.S. in Civil Engineering from UC Davis in 1978, a M.S. in Civil Engineering from University of Nevada Reno in 1982, and a Ph.D. in Civil Engineering from University of Nevada Reno in 
1988. Since 1989 he has served on the faculty at the University of Alabama in Civil and Environmental Engineering. His research interests include structures and engineering education.

TAN-YU LEE received a B. S. in Mathematics from National Taiwan University in 1968 and a Ph.D. in Mathematics from UC Santa Barbara in 1979. Since 1980 he has served on the faculty at the University of Alabama in Mathematics. His research interests include optimization, queuing theory and mathematics education.

JOHN DANTZLER, Ph.D. is the President of Censeo Research, Inc., a program evaluation consulting company, and has worked with engineering education data analysis for five years. He holds a Ph.D in Educational Research and has assisted with the evaluation and analysis of engineering-related collaborative learning programs, inventory development, and diversity issues with the University of Alabama and the Foundation Coalition. 


\section{Math Problem Solving Assessment}

Solve the following problems. Show all your work. Calculators are not permitted.

1. An experimental atomic layer deposition (ALD) process can produce a layer of iron on a silicon wafer that is one atom thick. On a certain run, the process deposits a total of $30,668,000$ atoms. If there are 614,360 atoms deposited per square micron, ABOUT how many square microns are covered? Note: There are $10^{6}$ microns in a meter.

2. Bill's health food store stocks only two items, Sugar Frosted Flakes and barbeque sauce. He is open for 9 hours every day, 6 days a week. One morning, when he opens the doors, he notices he has 108 items on the shelves. He has an especially good day and sells everything in the store. When counting the money at the end of the day, he notices he took in a total of $\$ 420$. If a box of Sugar Frosted Flakes sells for \$5.00, and a jar of barbeque sauce sells for $\$ 3.00$, how many boxes of Sugar Frosted Flakes did Bill sell that day? Food items are exempt from sales tax in Bill's state.

3. You want to construct an open square box with no top by taking a square piece of cardboard, cutting squares out of the corners and folding up the sides. If the sides of the box are 4" high, how large a piece of cardboard do you need to make a box that holds a volume of 144 cubic inches? You may neglect the thickness of the cardboard.

4. The following problem does not contain all the data necessary to solve it. Clearly identify what additional data is needed. Then plug in the value 2 for all missing data and solve the problem.

A rectangular swimming pool has a uniform depth of 8 feet. It takes a good swimmer 20 seconds to swim the length of the pool, and 10 seconds to swim across the pool. How long in seconds does it take to fill the pool with water? 
5. A workman places a 12 " by 12 " square stool with four legs on top of the roof of a typical house (i. e. with a single ridge down the middle, and sloping equally on each side) so that the surface of the stool is level. The legs are square, vertical, and flat on the bottom. The space between the legs on any side of the stool is 8 ", and each side of the roof is at a $33^{\circ}$ angle from horizontal. If the stool is $12^{\prime \prime}$ high, and the house is $30^{\prime}$ high, $50^{\prime}$ long, and 30 ' wide, how high is the top of the stool above the ground? You may leave any trigonometric, exponential, square root or logarithmic expressions unevaluated. So 2 $\cos \left(15^{\circ}\right)$ would be ok as an answer.

6. Eight robbers stole a sack of diamonds from a jewelry store. After returning to their hideout, they divided up the diamonds and 3 were left over. In the ensuing brawl over the 3 diamonds, one robber was killed. The diamonds were again divided among the 7 robbers and 3 were left over. The gang leader decided that he should get the 3 left over diamonds and was promptly shot, so the 6 remaining robbers divided up the diamonds and again 3 were left over. Feeling despondent and in fear for his own life, one of the robbers just gave up and left. Finally, this time the diamonds were divided evenly among the remaining 5 robbers. What is the least number of diamonds in the sack? 


\section{Self-Appraisal Inventory}

Indicate the degree to which you agree or disagree with the following statements on a scale of $1-10$.

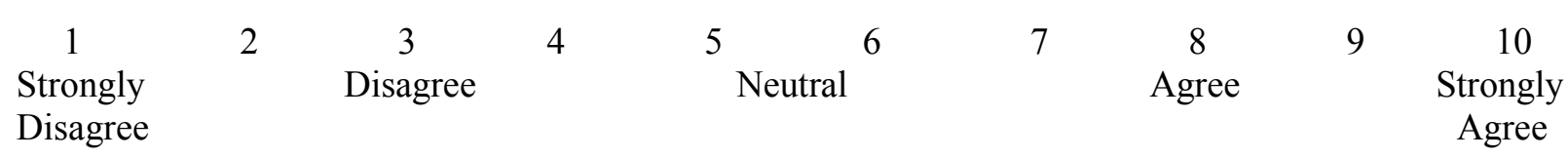

_ 1. I am good at solving mathematics problems.

- 2. When I read a mathematics problem, I can identify the mathematics concepts I need to solve the problem.

3. When given a mathematics problem, I usually can find more than one approach that has a good chance of successfully solving the problem.

- 4. I can check my solution to a mathematics problem and feel confident my answer is correct.

_ 5. I am good at solving word problems.

_ 6. I can draw diagrams that give me insight into how to solve a mathematical problem.

- 7. When I work a difficult mathematics problem, I can identify other problems I have seen before that contain ideas that help me solve the problem at hand.

8. I can introduce mathematical notation, such as additional variable names, that helps me solve problems.

- 9. When I work a complicated mathematics problem, I can find simpler sub-problems that I can use to solve the original problem.

10. If I get stuck when working a mathematics problem, I keep working for a long time because I know that I can eventually solve it.

Suppose that you were asked the following math questions. Please indicate how confident you are that you could solve the problem correctly. Assume you can use a calculator unless stated otherwise. Do not attempt to solve the problems.

Please use the following scale from $1-10$, with

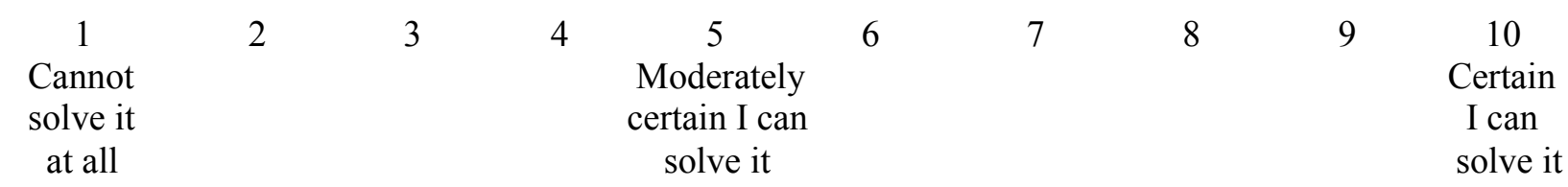


11. In a certain triangle, the sum of the sides is 24 inches. The longest side is twice as long as the shortest side, and the third side is 3 inches shorter than the longest side. What is the length of the longest side?

12. ABOUT how many times larger than 514,360 is $20,668,000$ ? Do not use a calculator.

13. Bridget buys a packet containing 9 cent and 13 cent stamps for $\$ 2.65$. If there are 25 stamps in the packet, how many are 13 cent stamps?

14. On a certain map, $7 / 8$ inch represents 200 miles. How far apart are two towns whose distance apart on the map is $3 \frac{1}{2}$ inches.

15. Five math tests are given to Mary's class. Each test has a value of 25 points. Mary's average for the first four tests is 20 . What is the highest possible average she can have on all 5 tests?

16. In a small auditorium the chairs are usually arranged so there are 5 rows and 10 seats in each row. For a popular speaker, extra rows are added, and the same number of extra seats is added to each row (if you add 3 rows, you then add 3 seats to each row, including the new ones). Find the number of rows that must be added to triple the total number of seats in the auditorium.

17. Solve $\frac{2}{x+1}+\frac{4}{x+2}=3$ for $\mathrm{x}$.

18. Solve $\sqrt{2 x}=\sqrt{x+1}+1$ for $\mathrm{x}$.

19. Solve $5^{4-x}=7^{3+x}$ for $\mathrm{x}$.

20. Machine A can harvest all the wheat in certain field in 6 hours. Machine B can harvest the same field in 10 hours. How long would it take the two machines, working together, to harvest the field.

21. A rectangle is inscribed inside a circle with radius $r$, (all four corners are on the circle). Express the area $\mathrm{A}$ of the rectangle in terms of the length $\mathrm{x}$ of one side of the rectangle and $\mathrm{r}$.

22. A function $\mathrm{f}(\mathrm{x})$ is even if $\mathrm{f}(\mathrm{x})=\mathrm{f}(-\mathrm{x})$, and odd if $\mathrm{f}(\mathrm{x})=-\mathrm{f}(-\mathrm{x})$. For any function $\mathrm{g}(\mathrm{x})$, prove that $\mathrm{g}(\mathrm{x})+\mathrm{g}(-\mathrm{x})$ is even, and $\mathrm{g}(\mathrm{x})-\mathrm{g}(-\mathrm{x})$ is odd.

- 23. Without using a calculator, determine which number is bigger, $\sqrt[10]{10}$ or $\sqrt[3]{2}$ ?

- 24. Find the equation of a straight line passing through the points $(x, y)=(1,2)$ and $(x, y)=(-1,1)$.

25. A flagpole stands in a flat open field. Fred puts his head next to the ground 50 feet from the pole, looks up at the top of the pole, and determines he is looking up at an angle of $20^{\circ}$. Find the height of the flagpole. 